\title{
Hydrodynamic Performance and Cavitation Analysis in Bottom Outlets of Dam Using CFD Modelling
}

\author{
Omid Aminoroayaie Yamini $\left(\mathbb{D}\right.$, S. Hooman Mousavi ${ }^{D}$, M. R. Kavianpour $(\mathbb{D}$, \\ and Ramin Safari Ghaleh
}

Department of Civil Engineering, K. N. Toosi University of Technology, Tehran, Iran

Correspondence should be addressed to Omid Aminoroayaie Yamini; o.aminoroaya@mail.kntu.ac.ir

Received 11 January 2021; Revised 25 April 2021; Accepted 6 May 2021; Published 18 May 2021

Academic Editor: Faming Huang

Copyright (c) 2021 Omid Aminoroayaie Yamini et al. This is an open access article distributed under the Creative Commons Attribution License, which permits unrestricted use, distribution, and reproduction in any medium, provided the original work is properly cited.

\begin{abstract}
Bottom outlets are significant structures of dams, which are responsible for controlling the flow rate, operation, or removal of reservoir sedimentation. The service gate controls the outlet flow rate, and whenever this gate is out of order, the emergency gate which is located at upstream is utilized. The cavitation phenomenon is one of the common bottom outlets' problems due to the rapid flow transfer. The present research is a numerical study of the flow pattern in a dam's bottom outlet for different gate openings by the use of Flow-3D software and RNG $k-\varepsilon$ turbulence model. The investigation is carried out on the Sardab Dam, an earth dam in Isfahan (Iran). The maximum velocity for 100\% opening of the gate and Howell Bunger valve is about $18 \mathrm{~m} / \mathrm{s}$ in the section below the gate, and the maximum velocity for $40 \%$ opening of the gate is equal to $23.1 \mathrm{~m} / \mathrm{s}$. For $50 \%$ opening of the service and emergency gate in the valve's upstream areas, the desired pressure values are reduced. Moreover, in the areas between the two emergency and service gates, the pressure values are reduced. The possibility of cavitation in this area can be reduced by installing aerators. The flow pattern in Sardab Dam's bottom outlet has relatively stable and proper conditions, and there are no troublesome hydraulic phenomena such as local vortices, undesirable variations in pressure, and velocity in the tunnel, and there is no flow separation in the critical area of flow entering into the branch.
\end{abstract}

\section{Introduction}

Bottom outlets are utilized as one of the dam's hydraulic structures to control the reservoir impoundment, the reservoir evacuation in case of emergency, and the removal of the sediments entering the reservoir. Hence, they require careful design and harmful factors identification [1]. On the other hand, to ensure the channel's proper operation, its associated hydraulic and hydromechanical installations, including gates and valves, the flow discharge capacity should be carefully examined along with performing hydraulic model tests [2]. By studying failure causes of dams' terminal gates, it has been determined that the cavitation phenomenon and gate vibration are the chief reasons for damages, because, in the areas where air bubbles collapse, pressure fluctuations intensity raises [3-8]. At the bottom outlets, the two-phase air-water flow is transmitted at high speed. Due to the division of the flow and its impromptu conversion from the pressurized flow to the free-surface flow, a sharp loss in pressure values downstream of the gate occurs. Cavitation is one of the destructive phenomena that happen because of such negative pressure. Aeration by aerator tube is usually employed in order to control this phenomenon [9-12].

Sadat Helbar et al. (2021) studied on the size and shape of bottom outlet gates, which affect the outflow discharge, and flushing efficiency. The purpose of their study was to investigate the effect of the area, shape, and number of the bottom outlet gates on the velocity and concentration of the sediments [13].

In these structures, due to the high-velocity flow and the channel's water level fluctuation, the flow may separate from the channel's wall, and flow pressure may reduce locally. If the flow pressure is less than the water vapor pressure, the 
water state shifts from a liquid to a gas, and air bubbles form. The flow may carry air bubbles to a higher pressure area in order to collapse, and a negative pressure wave enters the flow. If air bubbles explode near the wall's surface, they can damage the channel's wall [14-16]. Yang et al. (2020) worked on a 3D CFD modeling to show the water-air flow behavior. Air demand varies considerably between flow cases. It is not the simultaneous discharge of all openings that results in the largest air demand [17].

The service gate's downstream area and the area between the emergency gate and the service gate, as well as the gate slots that create an uneven surface against the flow hold the highest risk of cavitation $[18,19]$. The cavitation index, a function of local pressure and flow velocity, is used as an essential parameter to assess the potential for cavitation [20]. Daneshmand et al. (2007) experimentally studied flow's hydraulic characteristics at different service gate openings in Sivand Dam's bottom outlet. Their study showed an increase in the amount of flow turbulence in the emergency gate slit with the service gate opening from $85 \%$ above, and also the cavitation index in all openings is more than the critical limit [21]. Two cavitation index control methods can control cavitation damage by modifying the structure geometry and flow aeration [22]. Kavianpour (1997) performed experiments to determine aeration's effect on slopes downstream pressure fluctuations. They concluded that air intake lessens severe pressure fluctuations and raises its mean, which in turn reduces cavitation likelihood. They also studied flow aeration's effect on the pressure field's structure, including the energy spectrum of fluctuations, skewness, the sharpness of fluctuations, and negative pressure fluctuations' risk reduction. This study showed that aeration changes the pressure field's structure [23]. Khazaei et al. (2015) studied the cavitation phenomenon in Rudbar Lorestan Dam's bottom intake numerically and in the laboratory. They showed that changing the channel's slope by 10 to $12 \%$, changing the channel's length by 1 to 3.5 meters, and reducing the channel walls' slope by 1 to 2 degrees can be a good option to eliminate the risk of cavitation [24].

Ruan et al. (2007) examined the hydraulic performance of aerators used at the base of Goupitan Dam's bottom discharge channel in a laboratory. The results indicate an increase in the inlet air flow rate into the stream in case of a decrease in the channel's slope after aeration. This correction has an effective role in protecting the discharge channel against cavitation damage [25]. Wu et al. (2007) studied hydraulic parameters such as flow pressure, water conductivity coefficient, and downstream flow profile at various service gate openings and diverse upstream channel heads in the Longtan Dam's bottom outlet in a laboratory. The results showed that the flow bottom's pressure values in channel gate's downstream rise with an increase in service gate opening, and the water conductivity coefficient in small and large is higher than the middle openings [26]. Li et al. (2020) investigated control gate opening's effect on pressure distribution and cavitation index with numerical and laboratory models. With basic assumptions such as a 45 -degree edge angle and a value of 2 for the length to width ratio of the gate (by keeping the gate height constant), they conducted their research on $10,30,50$, and $100 \%$ opening of control gate with different 2-, 3-, and 4-meter heads. The result is that the cavitation index is high in $10 \%$ and $100 \%$ openings of the control gate, so that in $30 \%, 50 \%$, and $70 \%$ gate openings, the probability of cavitation is higher [27].

Nikseresht et al. (2012) simulated the bottom intake No. 5 of Sefidrud Dam using a three-dimensional limited volume method and showed that the lowest pressure inside the tunnel occurs at $20 \%$ opening of the emergency gate, in which case the cavitation index is lower than the critical value. The use of aeration was proposed to eliminate the risk of cavitation. It is attempting to separate the high-velocity flow along the tunnel by using the appropriate system of aeration. Then, flow can be achieved in the tunnel lining when the risk of cavitation is decayed [28]. In this project, the channel's hydraulic performance and its geometry correction are evaluated for the proper functioning of the deep removal gates in different states of their opening. Since the deep removal gate divides the flow into two parts, the controller with agricultural irrigation valve and the controller with sliding valves through a branch, the study of different functional states has been considered. Single valve operation, single service gate function, and Howell Bunger valve and service gate's simultaneous operation are this project's objectives. Next, the channel's hydraulic operation in different agreed cases with the numerical model will be done, and the conclusion will be made.

1.1. Flow-3D Model and Governing Equations. Numerical simulation of the flow field in the bottom outlets and hydraulic structures in general, spillways, and energy dissipation systems are crucial for designing such structures. The experience of researchers in such simulations has shown that Flow-3D software has a better capability in modeling this type of hydraulic structures among the existing software packages. Flow-3D provides a complete and versatile CFD simulation platform for engineers investigating the dynamic behavior of liquids and gas in a wide range of industrial applications and physical processes. One of the significant features of the Flow-3D for hydraulic analysis is its ability to model free-surface flows, which are modeled using the VOF (volume of fluid) technique reported by Hirt and Nichols (1981) [29]. VOF is an advection scheme, a numerical recipe that allows the programmer to track the shape and position of the interface, but it is not a standalone flow solving algorithm. On the other hand, the equations governing fluid motion can be considered, which include the continuity equation for a control volume assuming incompressible flow and constant flow (equation (1)) and the momentum equation within a control volume considering turbulent (equation (2)) [30].

$$
\begin{gathered}
\frac{\partial U_{i}}{\partial x_{i}}=0 \\
\frac{\partial U i}{\partial t}+U_{j} \frac{\partial U_{i}}{\partial x_{j}}=-\frac{1}{\rho} \frac{\partial P}{\partial x_{i}}+\frac{\partial}{\partial x_{i}}\left(v \frac{\partial U_{i}}{\partial x_{j}}-\overline{u_{i}^{\prime} u_{j}^{\prime}}\right),
\end{gathered}
$$


where $\rho$ is the density of the fluid; $x_{i}$ and $x_{j}$ are the Cartesian coordinates; $U_{i}$ and $U_{j}$ are the Cartesian components of the velocity vector $v ; P$ is the pressure; and $\overline{u_{i}^{\prime} u_{j}^{\prime}}$ mean Reynolds stress tensor.

The two-equation model renormalization group (RNG) $k-\varepsilon$ is used to determine the Reynolds stress tensor in the momentum equation for turbulent flow. This model's equations are as follows:

The turbulent kinetic energy equation $K$ :

$$
\frac{\partial}{\partial t}(\rho k)+\frac{\partial}{\partial x_{i}}\left(\rho k U_{i}\right)=\frac{\partial}{\partial x_{j}}\left(\alpha_{k} \mu_{e f f} \frac{\partial k}{\partial x_{j}}\right)+G_{k}-\rho \varepsilon .
$$

The turbulent kinetic energy consumption rate equation $\varepsilon$ :

$$
\begin{aligned}
& \frac{\partial}{\partial t}(\rho \varepsilon)+\frac{\partial}{\partial x_{i}}\left(\rho \varepsilon U_{i}\right)=\frac{\partial}{\partial x_{j}}\left(\alpha_{\varepsilon} \mu_{e f f} \frac{\partial \varepsilon}{\partial x_{j}}\right)+C_{1 \varepsilon} \frac{\varepsilon}{k} G_{k} \\
& -C_{2 \varepsilon} \rho \frac{\varepsilon^{2}}{k}-R_{\varepsilon} .
\end{aligned}
$$

In the above equations, $\alpha_{k}$ and $\alpha_{\varepsilon}$ are the inverse effective Prandtl numbers for $k$ and $\varepsilon$, respectively. $C_{1 \varepsilon}$ and $C_{2 \varepsilon}$ are constants with values of 1.42 and 1.68 , respectively; $\mu_{\text {eff }}$ is the effective viscosity. The major difference between the RNG $k-\varepsilon$ model and the standard $k-\varepsilon$ model is that the RNG model has an additional term, $R_{\varepsilon}$, that significantly improves the accuracy for rapidly strained flows.

\section{Material and Methods}

2.1. Case Study of Sardab Dam's Outlet Channel with Howell Bunger Valve. Sardab Dam has been built on Sardab River in Iran. The dam site's height is 2712 meters above sea level' the dam's reservoir area is 270 hectares with a total reservoir capacity of 48 million cubic meters (Table 1).

Two sliding gates (service and emergency) with dimension (height $*$ width) $1.4 \times 1.1 \mathrm{~m}$ are located in a row inside the dam's bottom channel. Geometric details of Sardab Dam's bottom outlet is shown in Figure 1.

2.2. The Flow Rate Passing through the Channel during Gate Operation. In order to calculate the channel flow rate, assuming the gates are fully open, with the help of Bernoulli's equation and considering the channel loss, we have

$$
\mathrm{Q}=V_{d} A_{d}=A_{d} \sqrt{\frac{2 g H}{\sum \xi+\xi_{\text {out }}}},
$$

where $Q\left(\mathrm{~m}^{3} / \mathrm{s}\right)$ is the volume flow rate; $V_{d}(\mathrm{~m} / \mathrm{s})$ is the velocity in reference area; $A_{d}\left(\mathrm{~m}^{2}\right)$ is the cross-sectional reference area; $g\left(\mathrm{~m} / \mathrm{s}^{2}\right)$ is the gravitational acceleration; $H$ $(\mathrm{m})$ is the head; $\xi$ is the loss coefficient; and $\xi_{\text {out }}$ is the loss coefficient in outflow section.

In different parts of the channel, to calculate the total head loss and the total flow rate, a section should be selected as the reference, and the location under the gate is considered a reference section.
Head loss is the potential energy that is converted to kinetic energy. Head losses are due to the frictional resistance of the bottom outlet system (valves, gates, fittings, pipe, entrance, exit losses, etc.). To calculate the total head loss, we have

$$
\sum \xi \frac{V_{i}^{2}}{2 g}=\sum h_{f i}=1.4224 \frac{V_{o}^{2}}{2 g},
$$

where $V_{i}(\mathrm{~m} / \mathrm{s})$ is the velocity in each section; $V_{o}(\mathrm{~m} / \mathrm{s})$ is the velocity in reference area; and $h_{f i}(\mathrm{~m})$ is head loss.

The contraction coefficient due to the constriction for the 45 -degree angle will be about 0.95 .

$$
\xi_{\text {out }}=1.05\left(\frac{A_{d}}{\varepsilon A_{e}}\right)^{2} .
$$

In the above equation, $A_{e}\left(\mathrm{~m}^{2}\right)$ is the output cross-sectional area, $A_{d}\left(\mathrm{~m}^{2}\right)$ is the cross-sectional reference area, and $\varepsilon$ is the contraction coefficient of the cross-section compression function.

According to the theoretical issues stated and equations (5)-(7), the maximum volume flow rate passing through the channel is estimated to be $26 \mathrm{~m}^{3} / \mathrm{s}$ (velocity in reference area is $18.9 \mathrm{~m} / \mathrm{s}$ ). Table 2 and Figure 2 show the flow rate at different openings and heads.

2.3. Numerical Model. The first feature of Flow-3D is that it employs a highly variable rectangular gridding system for gridding. This characteristic makes the grid or geometry separable from each other. In simpler terms, it does not utilize a fixed grinding system connected to geometry or finite elements. It is also possible to use multiple gridding systems to increase efficiency and flexibility in gridding. The entire outlets flow rigid body is designed with all its details in three dimensions by SolidWorks software to model the bottom outlets' hydraulic conditions flow in Flow-3D software (Figures 3 and 4). It should be noted that five times the tunnel's diameter ( 7 meters) was added to the length and upstream of the tunnel to create a fully developed flow.

In order to cover the entire rigid body of the outlet with the branch valve, the mesh should be selected so that there is as little space as possible in the channel area as empty space. The following figures show the grid's details (12825258 cells), the computational cells, and the bottom outlet boundary conditions. It should be noted that the elements of the Flow$3 \mathrm{D}$ numerical model are of the cuboid element type. Size of the cells in mesh block $1,2,3$, and 4 in each direction $(X, Y$, and $Z$ ) is $2.3,2.3,3.7$, and $2.1 \mathrm{~cm}$, respectively. One of the issues that significantly affect the increasing calculation accuracy is determining the appropriate boundary conditions. There are six distinct aspects for defining boundary conditions in Cartesian coordinates, which according to the positive direction of the axes include $X_{\mathrm{Min}}, X_{\mathrm{Max}}, Y_{\mathrm{Min}}, Y_{\mathrm{Max}}$, $Z_{\mathrm{Min}}$, and $Z_{\mathrm{Max}}$. It is worth noting that all these specifications are defined in one block, and separate boundary conditions must be defined for each in the case of several blocks (Figures 5 and 6). The mechanism of applying boundary conditions to each aspect is such that after assigning each of 
Table 1: General specifications of Sardab Dam.

\begin{tabular}{lcccc}
\hline \multirow{2}{*}{ Dam } & Type & Crest elevation (m. a. s. l. $\left.{ }^{*}\right)$ & Dam Height $(\mathrm{m})$ & Crest length $(\mathrm{m})$ \\
& Earth dam & 2528 & 53 & 752 \\
\hline \multirow{2}{*}{ Reservoir } & Maximum water level (PMF) $(\mathrm{m})$ & Normal water level $(\mathrm{m})$ & Minimum water level $(\mathrm{m})$ & Minimum volume $\left(\mathrm{m}^{3}\right)$ \\
& 2527 & 2524.6 & 2488.6 & $1,000,000$ \\
\hline
\end{tabular}

${ }^{*}$ Meters above sea level.

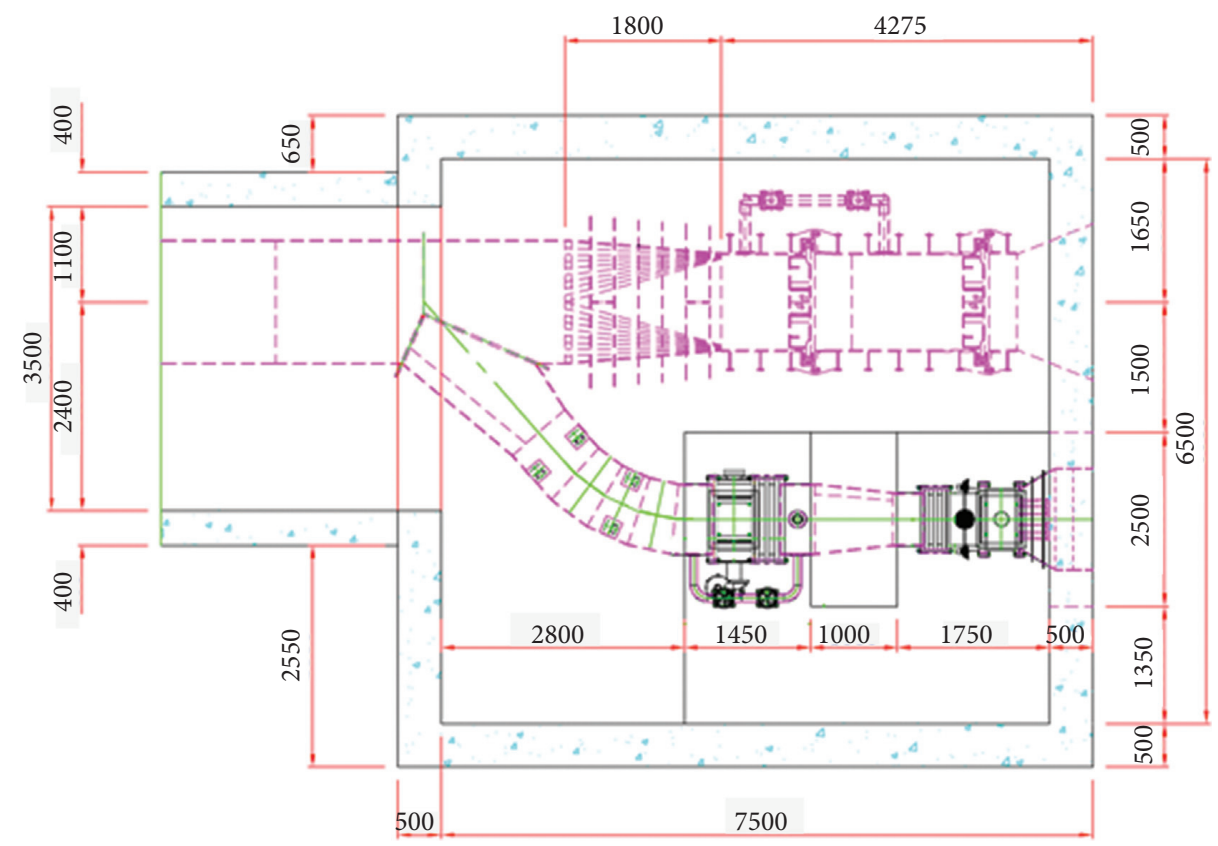

Figure 1: Geometric details of Sardab Dam's bottom outlet (all dimensions are in $\mathrm{mm}$ ).

TABLE 2: The flow rate passing through the channel in the openings of service gates and different heads.

\begin{tabular}{lccccccc}
\hline$a / a_{\mathrm{o}}$ & $H_{\max }=51.35 \mathrm{~m}$ & $H=48.95 \mathrm{~m}$ & $H=45 \mathrm{~m}$ & $H=40 \mathrm{~m}$ & $H=35 \mathrm{~m}$ & $H=30 \mathrm{~m}$ & $H=20 \mathrm{~m}$ \\
\hline 0.1 & 3.17 & 3.1 & 2.97 & 2.8 & 2.62 & 2.43 \\
0.2 & 6.29 & 6.15 & 5.89 & 5.56 & 5.2 & 4.81 & 7.98 \\
0.3 & 9.29 & 9.07 & 8.7 & 8.2 & 7.67 & 5.93 \\
0.4 & 12.18 & 11.9 & 11.41 & 10.75 & 10.06 & 9.31 \\
0.5 & 15.03 & 14.67 & 14.07 & 13.26 & 12.41 & 11.49 & 7.6 \\
0.6 & 17.67 & 17.25 & 16.54 & 15.59 & 14.59 & 13.5 & 11.03 \\
0.7 & 20.06 & 19.59 & 18.78 & 17.71 & 16.56 & 15.33 \\
0.8 & 22.29 & 21.77 & 20.87 & 19.68 & 18.41 & 17.04 \\
0.9 & 24.35 & 23.77 & 22.8 & 21.49 & 20.1 & 12.52 \\
1 & 26.64 & 24 & 24.93 & 23.51 & 21.99 & 13.91 \\
\hline
\end{tabular}

the states to one aspect, all cell inputs of that aspect enter the equations with the above boundary condition. This is fixed at different times of solving equations and running the software. Pressure can be defined as the amount of pressure or as stagnation pressure. The amount of fluid can also be specified as a percentage of the fluid fraction or as fluid height for the software. Fluid velocity in all three directions can be entered in the software. The software also can receive each of the above parameters as a time series [31-33].

In the present research, a mesh sensitivity analysis was conducted with 5 different cell sizes. Table 3 shows the results of the mesh sensitivity analysis on the velocity in reference area for $100 \%$ gate and valve opening. As can be seen, if the cell size is smaller than main mesh, it does not affect the accuracy of simulation and if the cell size is larger than main mesh, error can increase about twice.

\section{Results and Discussion}

3.1. Evaluation of Numerical Modeling Results with Flow-3D Software. In order to evaluate the numerical model results' calibration and validation in various bottom outlet's gate openings, the output flow rate of the manual analysis should be compared with the output flow rate of the numerical model for the same applied head conditions using the analytical solution performed in the previous sections 


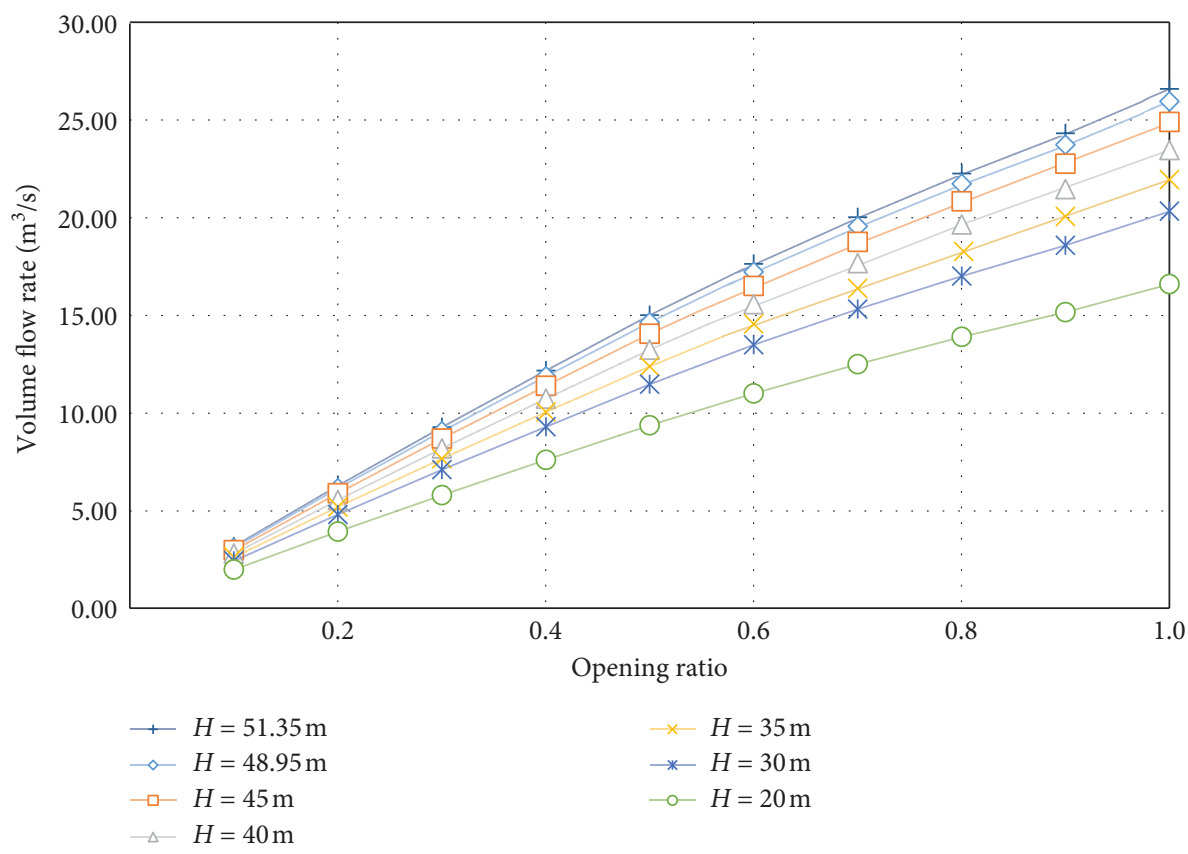

FIGURE 2: The volume flow rate at different openings and heads.
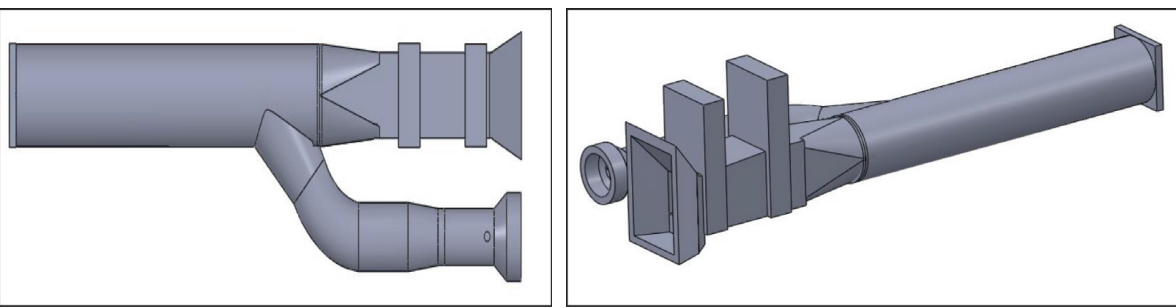

FIgURE 3: Complete bottom outlet geometry with Howell Bunger valve, aerator, and butterfly valve made in SolidWorks software.
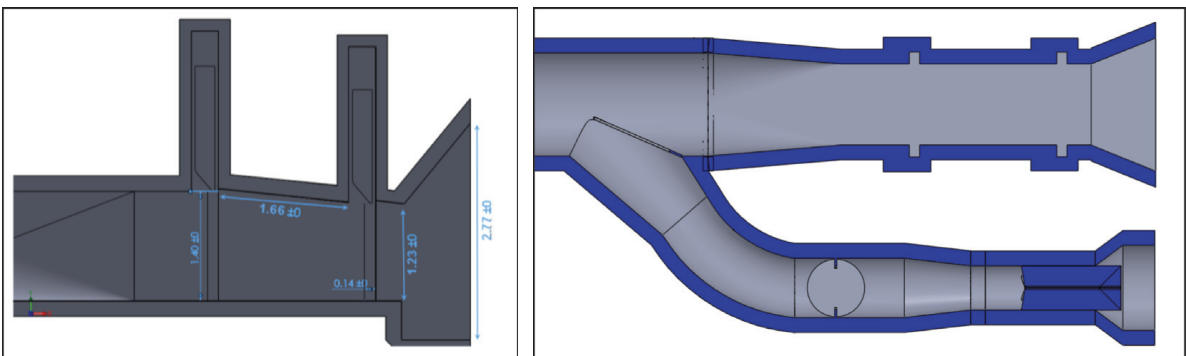

Figure 4: Details of construction of 3D geometry of Sardab Dam's bottom outlet (all dimensions are in $\mathrm{m}$ ).
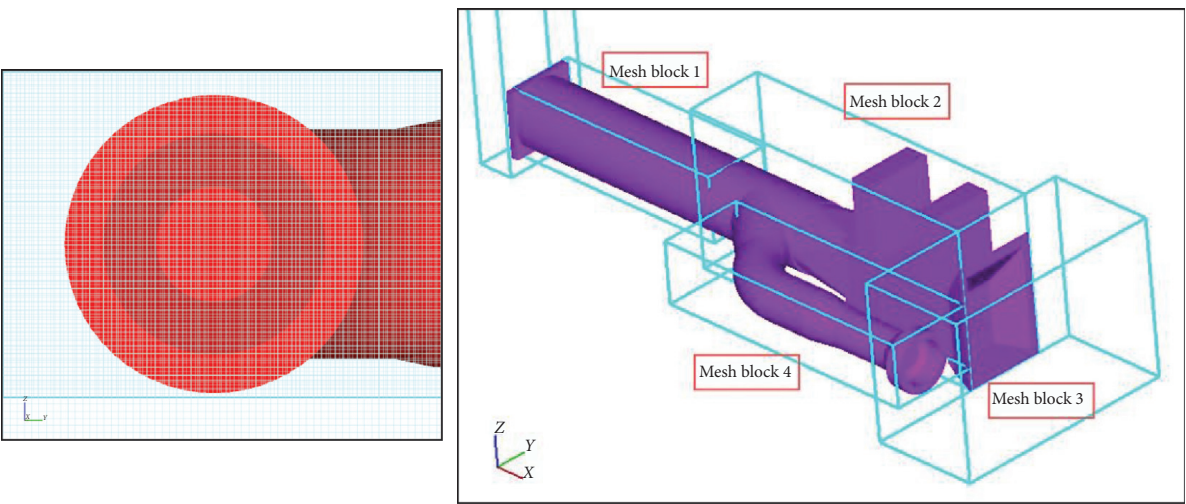

FIGURE 5: Numerical model's gridding and meshing blocks for bottom outlets and branch in Flow-3D numerical model. 


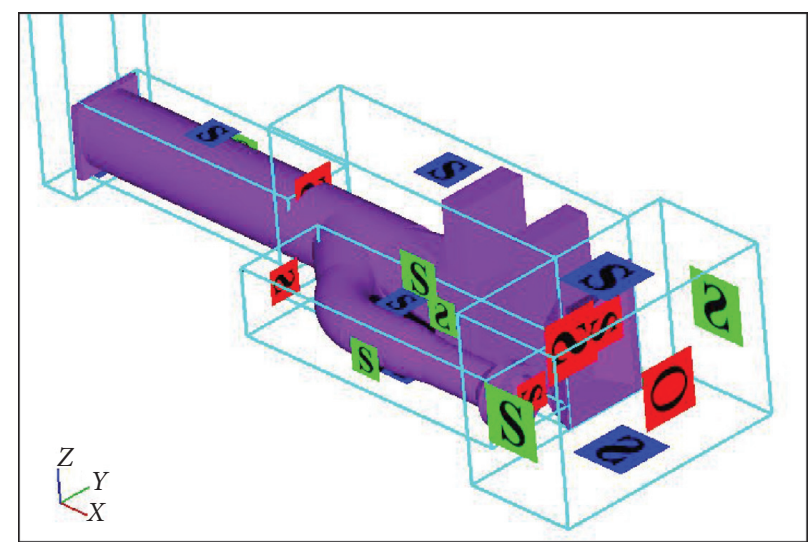

Figure 6: Boundary conditions applied in flow simulation in the bottom outlets.

TABLE 3: Mesh sensitivity analysis.

\begin{tabular}{lccccc}
\hline \multirow{2}{*}{ Parameters } & & \multicolumn{3}{c}{ Type of mesh } \\
& Cell size 20\% smaller & Cell size 10\% smaller & Main & Cell size 10\% larger & Cell size 20\% larger \\
\hline Velocity $(\mathrm{m} / \mathrm{s})$ & 18.21 & 18.13 & 18.05 & 17.42 & 17.1 \\
Analytical velocity $(\mathrm{m} / \mathrm{s})$ & 18.9 & 18.9 & 18.9 & 18.9 & 18.9 \\
Error $(\%)$ & 3.65 & 4.07 & 4.49 & 7.83 & 9.52 \\
\hline
\end{tabular}

(Figure 7). In the mentioned destructive phenomena, parameters such as flow rate, velocity, water's hydrodynamic pressure, air velocity entering the flow, and water depth are effective. By measuring some of these parameters, they can be prevented from happening before failure [34]. Furthermore, due to the governing equations' nature, it is essential to start the flow analysis with fixed boundary conditions so that eventually the flow reaches a steady state after a suitable time in the model. The output flow rate values of the steady flow state in the numerical model are compared with the analytical solution results in Figure 8. It is noteworthy that the numerical model's head is considered based on the standard head of 48.95 meters, and the branch valve's opening is considered $100 \%$ open [35].

As indicated in Figure 8, by calculating the mean relative error, the numerical model's output flow rate in different openings of Sardab Dam's bottom outlet gate is about $4 \%$, which is an acceptable and petite amount. Hence, based on these conditions, Flow-3D numerical modeling is calibrated and validated, and other required hydraulic parameters, including pressure values, velocity, and hydraulic field of flow in the bottom outlet's sensitive points, can be investigated. Figures 9 and 10 show the Sardab Dam's bottom outlet's output flow rate values at different openings with the analytical solution results.

3.2. Numerical Modeling Results for 5 Modes of Gate and $100 \%$ Branch Valve Opening. The results manifested in Table 4 are for openings including 20,40,60,80, and $100 \%$ at a standard head height of 48.95 meters. Table 4 presents the changes' values in the bottom outlet's output flow rate for different gate openings.

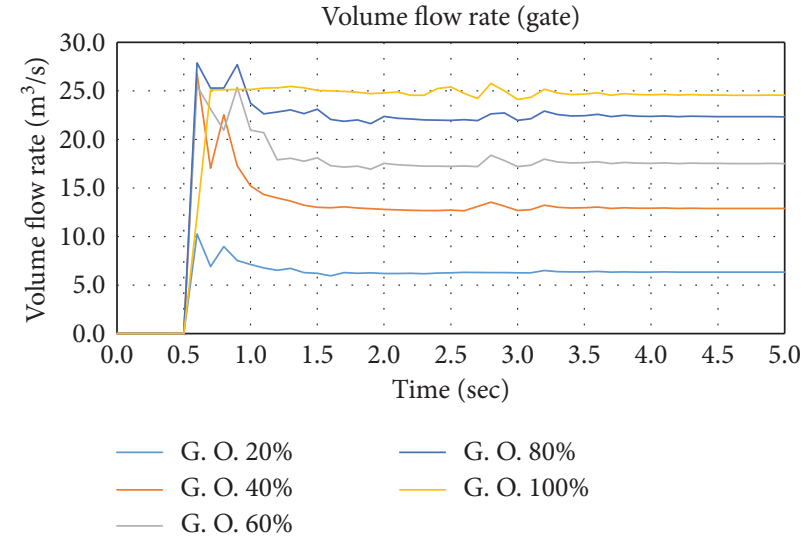

FIgURE 7: Numerical model results for output flow rate at various gate openings during Flow-3D numerical model implementation.

3.3. Velocity Changes in Different Gate Conditions. The hydraulic parameter modeling results show that the velocity value at $100 \%$ opening in the section below the gate is about $18 \mathrm{~m} / \mathrm{s}$ (Figure 11). The maximum velocity under the gate for $40 \%$ opening is $23.1 \mathrm{~m} / \mathrm{s}$ (Figure 12). The velocity values at $80 \%, 60 \%$, and $20 \%$ can be found in Figures 13-15, respectively. Velocity values examination in sensitive points, including gate slots, in the input flow areas to the branch valve, shows that undesirable hydraulic changes do not occur, and severe changes in velocity increase are not observed in these areas [36].

The gate slot's velocity values are about $2-3 \mathrm{~m} / \mathrm{s}$, in which case no flow separation and undesirable circular flow are observed in the slot. These conditions function almost the 


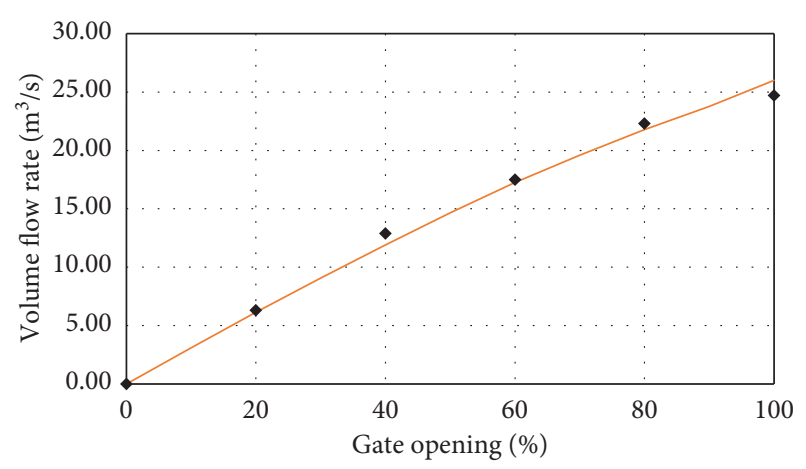

- Numerical: Flow-3D Analytical

FIGURE 8: Comparison of analytical solution results and numerical modeling of output flow rate in varying valve openings.

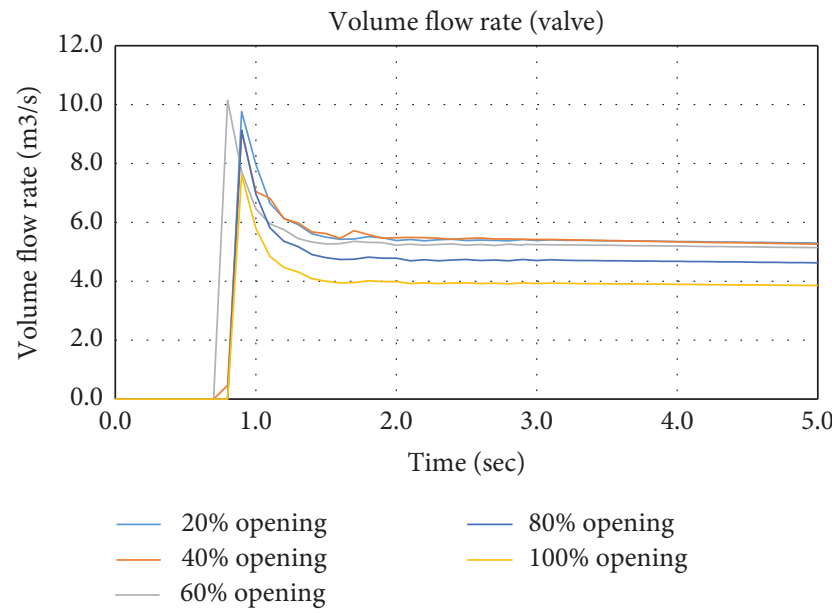

Figure 9: Results of Flow-3D numerical model for the valve's output flow rate at the service gate's different openings during model execution.

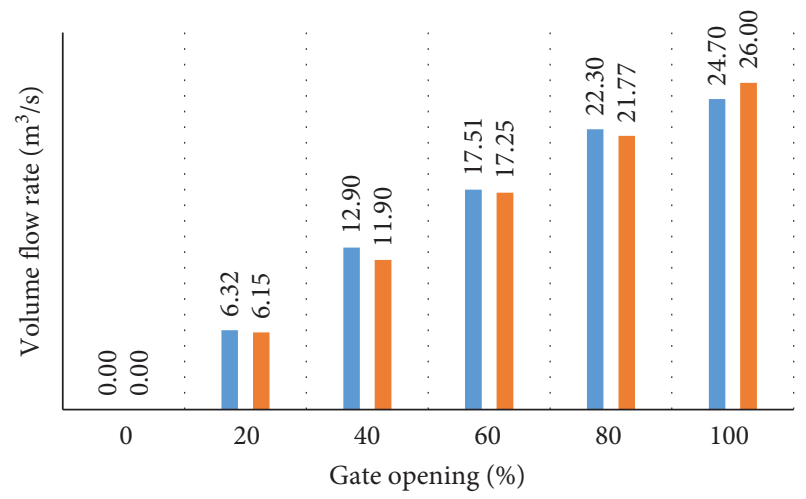

- Numerical: Flow-3D

- Analytical

FIGURE 10: Comparison of analytical solution results and numerical modeling of output flow rate in different gate openings.
TABLE 4: Changes in bottom outlet's output flow rate for different gate openings.

\begin{tabular}{lcc}
\hline Gate openings $(\%)$ & $\begin{array}{c}\text { Flow rate (gate) } \\
\left(\mathrm{m}^{3} / \mathrm{s}\right)\end{array}$ & $\begin{array}{c}\text { Flow rate (valve) } \\
\left(\mathrm{m}^{3} / \mathrm{s}\right)\end{array}$ \\
\hline 0 & 0.00 & 0.00 \\
20 & 6.32 & 5.30 \\
40 & 12.90 & 5.26 \\
60 & 17.51 & 5.14 \\
80 & 22.30 & 4.63 \\
100 & 24.70 & 3.86 \\
\hline
\end{tabular}

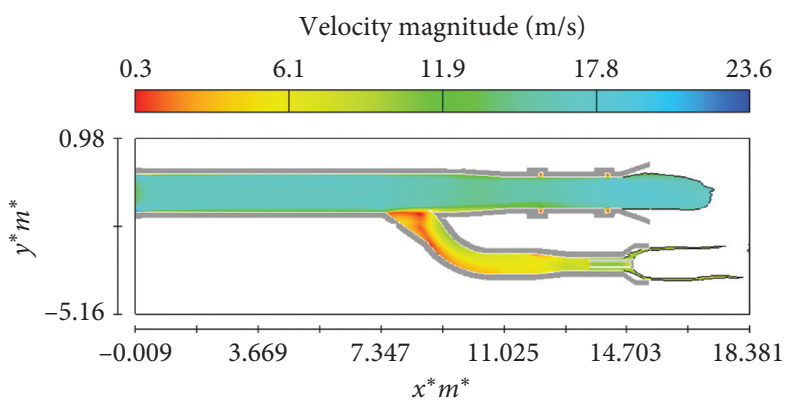

FIGURE 11: Output velocity of the gate and valve in $100 \%$ gate and valve opening.

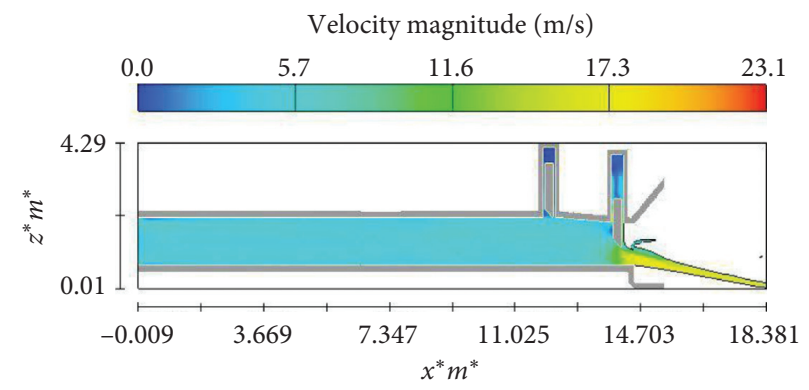

FIgURE 12: Output velocity of the gate and valve in $40 \%$ gate and $100 \%$ valve opening.

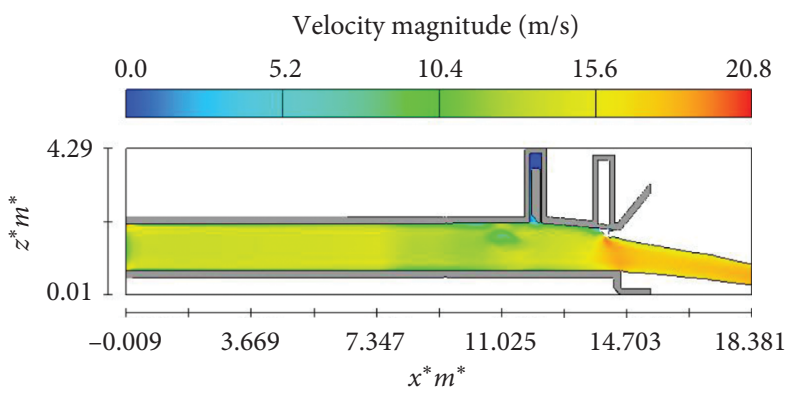

Figure 13: Output velocity of the gate and valve in $80 \%$ gate and $100 \%$ valve opening. 


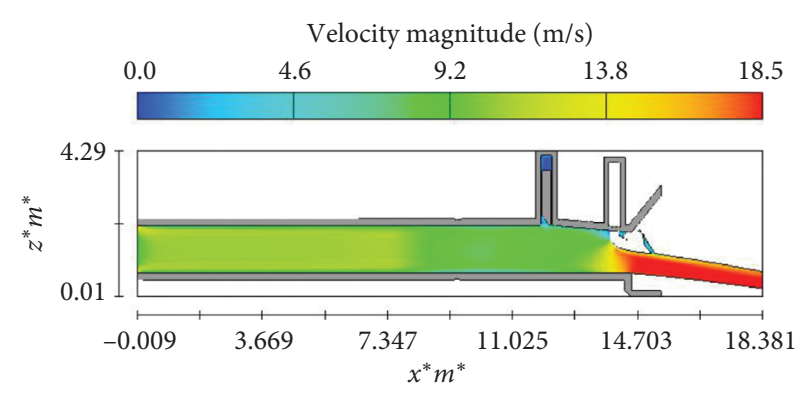

Figure 14: Output velocity of the gate and valve in $60 \%$ gate and $100 \%$ valve opening.

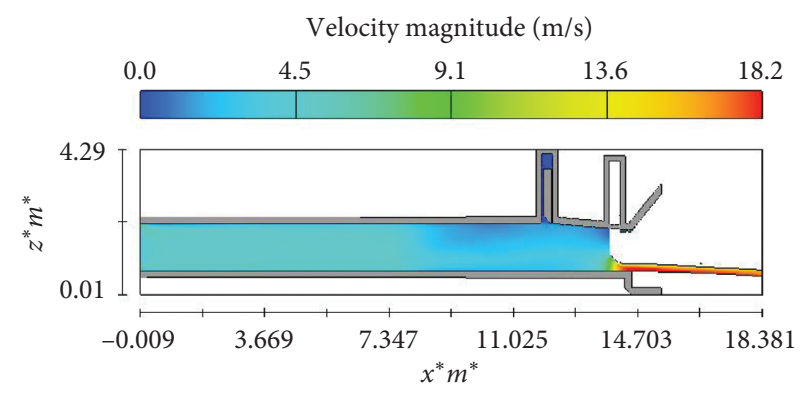

Figure 15: Output velocity of the gate and valve in $20 \%$ gate and $100 \%$ valve opening.

same for all openings. Figure 16 shows the velocity change's size and vectors in the gate slots at $100 \%$ gate opening.

Investigation of velocity values in the branch and stiffener area is presented in Figure 17. There is no flow separation and other adverse conditions in this area, and the velocity values at the branch entrance are variable, $2-5 \mathrm{~m} / \mathrm{s}$. The velocity values increase after passing through the branch entrance.

\subsection{Changes in the Pressure Parameter under Different Gate} Openings. In outlet tunnels, the fluid movement may increase the pressure in the flow direction in the face of an obstacle. Such a pressure change is called the inverse pressure gradient. The fluid in this flow boundary layer area is affected by this increasing pressure so that this fluid velocity also slows down. However, because the fluid's kinetic energy within the boundary layer is low, it will likely stagnate and be reversed, causing the boundary layer to separate and deviate from it. The separation of the main stream from the boundary is called the separation phenomenon, which is caused by the reverse pressure gradient. A reverse pressure gradient is a necessary condition and not a sufficient condition for the separation of the flow. In other words, there can be a reverse pressure gradient without separation, while separation without a reverse pressure gradient cannot occur. The pressure amount in the channel area in different gate openings can be seen in Figures 18-21.

The flow under the gate creates a circular flow downstream, the main feature of which is a sharp pressure loss. This pressure loss is a function of the gate's opening, the

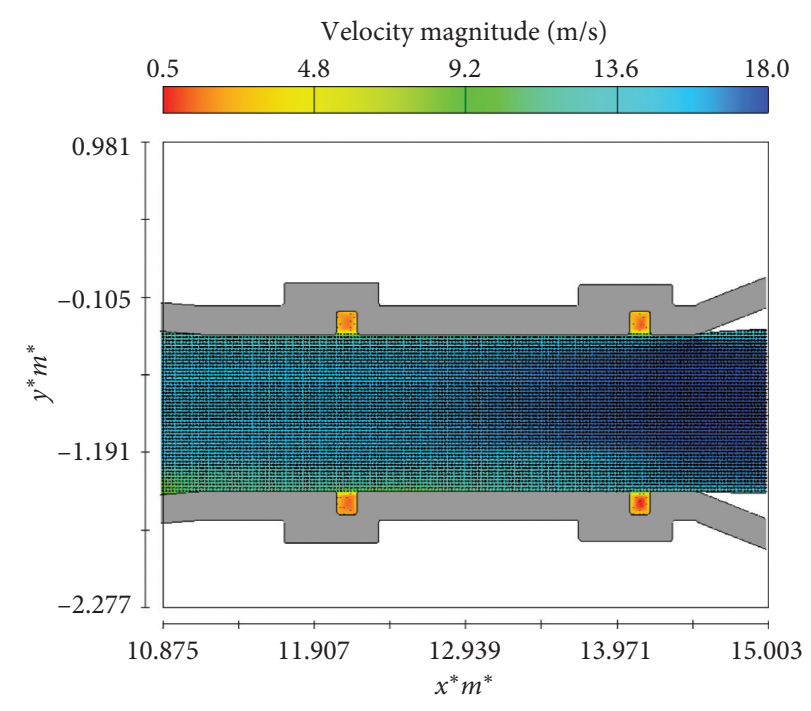

FIgURE 16: Velocity change's size and vectors in the gate slots at $100 \%$ gate and valve opening.

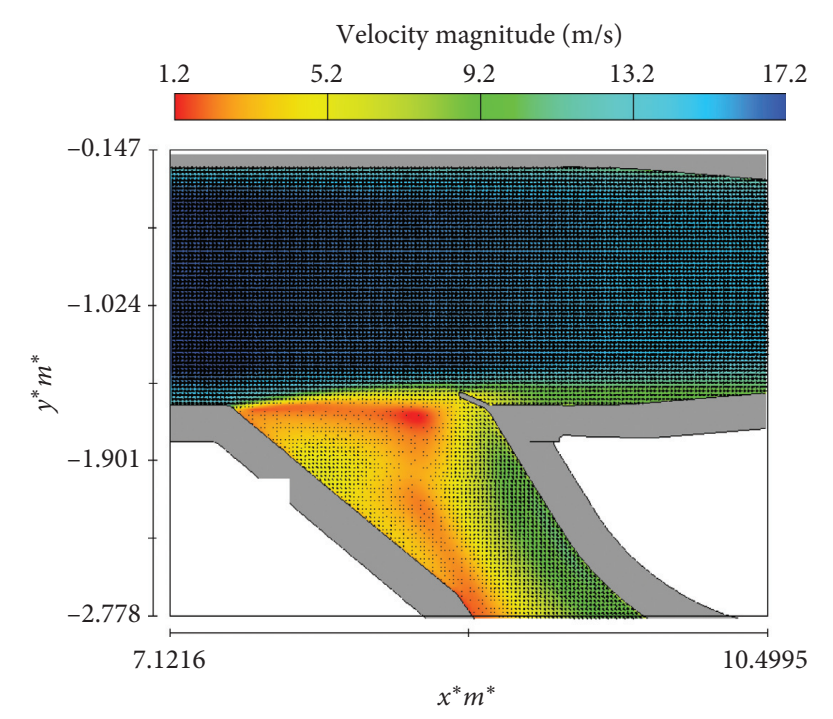

FIgURE 17: Velocity change's size and vectors in the branch area at $100 \%$ gate and valve opening.

water head behind the gate, and the channel's geometry. On the other hand, severe pressure fluctuations lessen that area's local pressure, and the potential for cavitation increases due to the high-velocity [37]. As can be seen in Figures 22-25, along the tunnel and in gate areas, gate slots, and branch area, undesirable severe pressure reduction did not occur, and there are no undesirable hydraulic phenomena such as flow separation and local vortices.

\subsection{Numerical Modeling Results for 50\% Emergency Gate and Service Gate Opening}

3.5.1. Fluid Volume Fraction Values per 50\% Service and Emergency Gates Opening. According to Figure 26, part of 

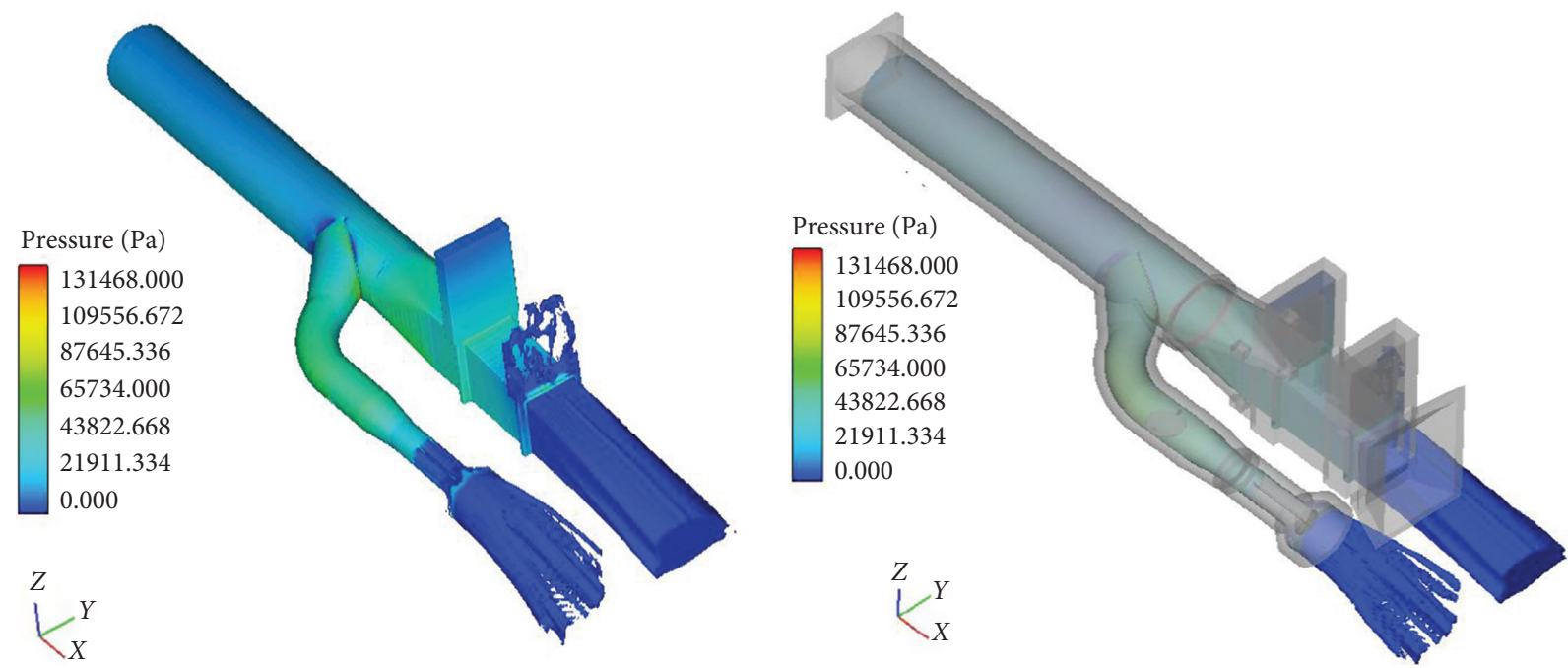

FIgURE 18: Three-dimensional view of the pressure in the whole model.

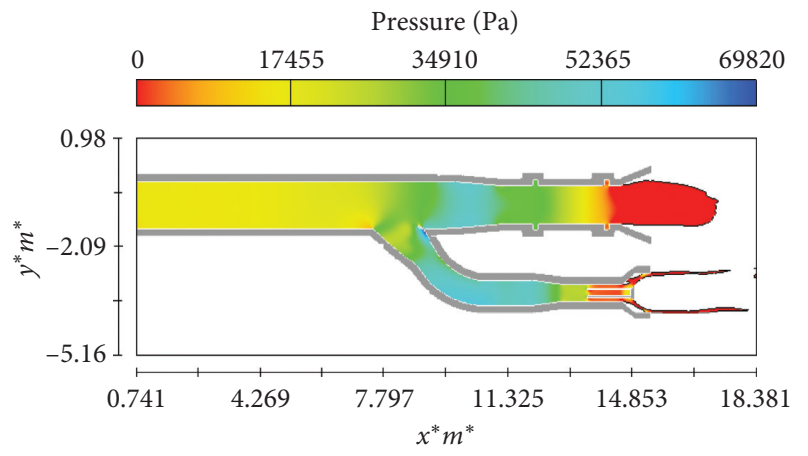

FIGURE 19: The pressure amount in the channel area leading to the gate and the branch in the state of $100 \%$ opening (100\% valve opening).

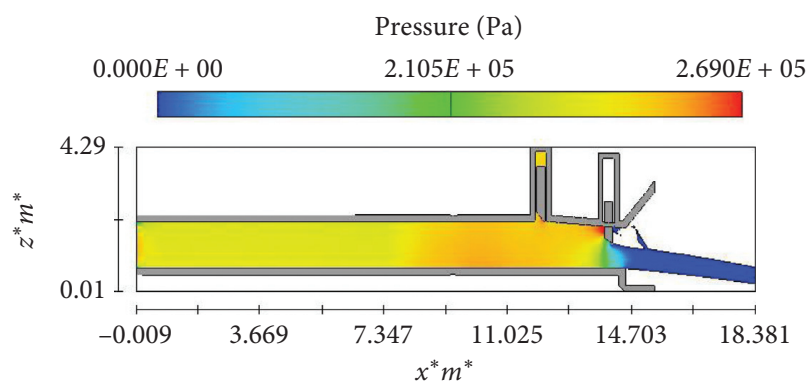

FIGURE 20: The pressure amount in the channel area leading to the gate and the branch in the state of $60 \%$ opening $(100 \%$ valve opening).

the aeration between the two gates is provided through the service gate.

3.5.2. Pressure Changes Values per 50\% Service and Emergency Gates Opening. As can be seen in Figures 27, in the gate's upstream areas, the desired pressure values are decreased, and in the areas between the two gates, the pressure

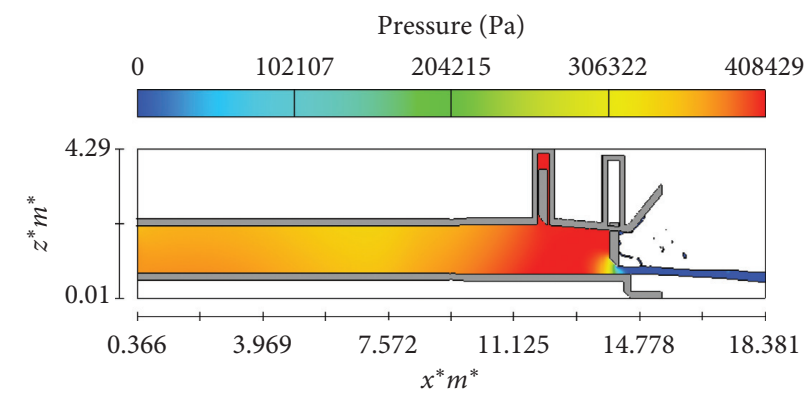

FIGURE 21: The pressure amount in the channel area leading to the gate and the branch in the state of $20 \%$ opening (100\% valve opening).

values are reduced. The possibility of cavitation in this area is reduced with the installation of aerators.

3.5.3. Numerical Modeling Results for Fully Closed Gate Mode and 100\% Open Branch Valve. The flow's hydraulic conditions are checked for the completely closed valve state and $100 \%$ open branch valve using numerical modeling in this case. 


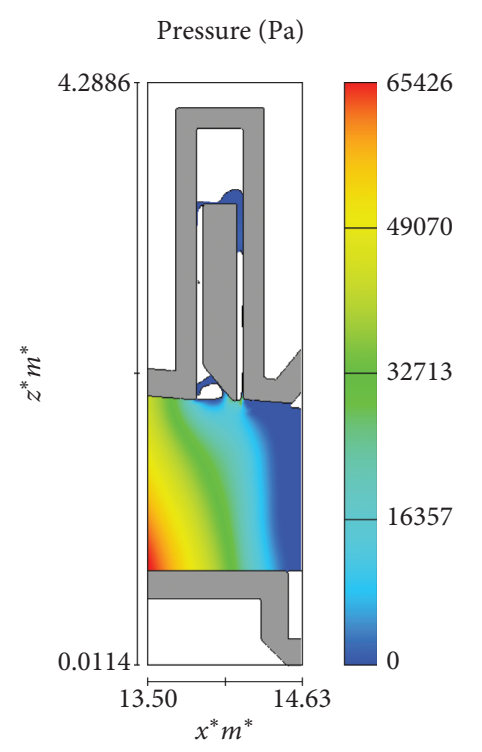

Figure 22: Pressure distribution under the gate for $100 \%$ opening mode (100\% valve opening).

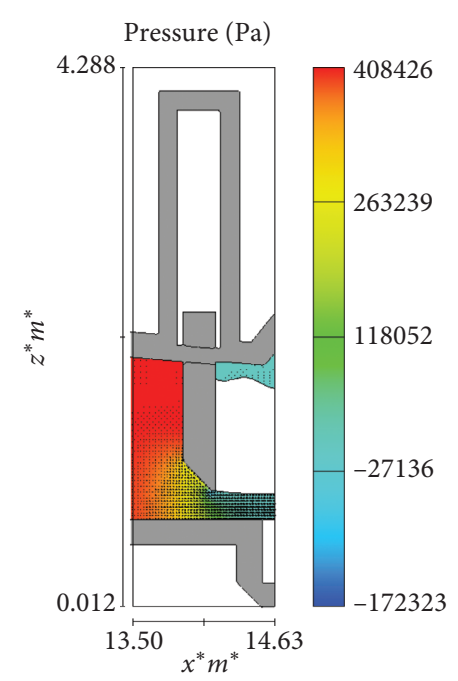

Figure 23: Pressure distribution under the gate for $20 \%$ opening mode (100\% valve opening).

3.5.4. Pressure Values in the Bottom Outlet's Tunnel of Sardab Dam and the Branch Area. As can be seen in Figures 28 and 29 , when the valve is completely closed, there is no circular flow and undesirable pressure changes in the tunnel.

3.5.5. Velocity Values in the Bottom Outlet's Tunnel of the Sardab Dam and the Branch Area. As can be seen in Figure 30 , the velocity behind the gates is zero in the fully closed state, and the velocity values at the branch entrance are 5$6 \mathrm{~m} / \mathrm{s}$. The velocity at the valve output has increased by about $36 \%$ compared to when the valves are fully open. Based on these conditions, the branch valve's output flow rate is estimated to be about $5.3 \mathrm{~m}^{3} / \mathrm{s}$.

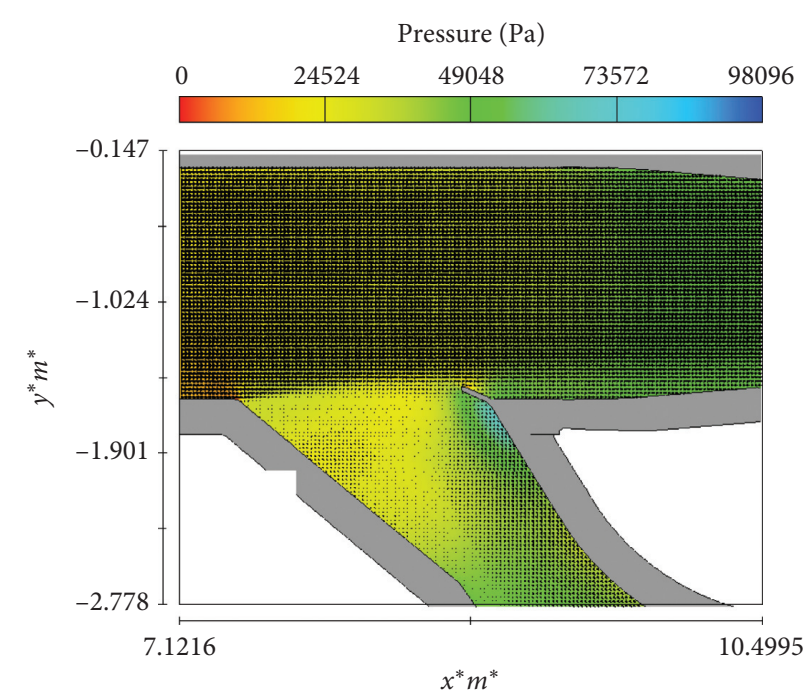

FIgURE 24: Flow pattern around the stiffener and no flow separation in this area (100\% valve opening).

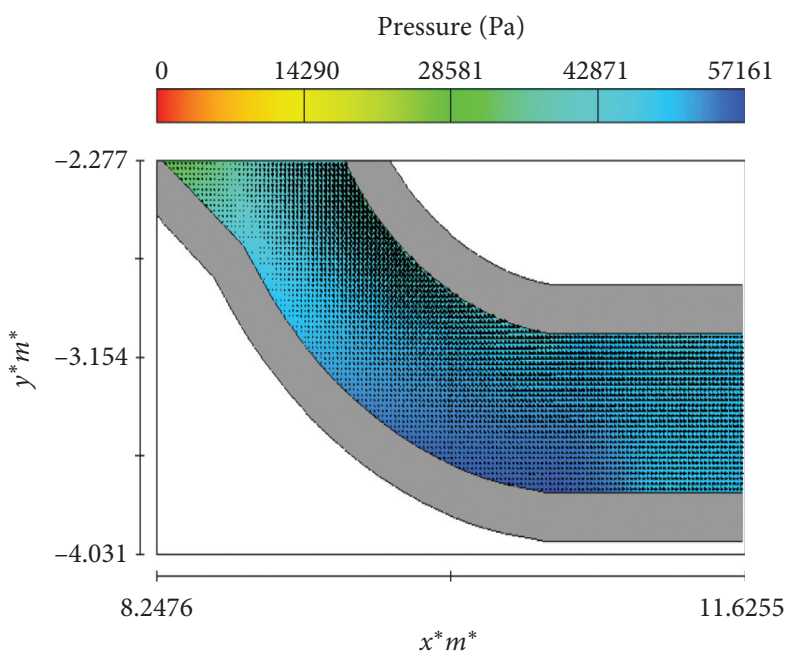

FIGURE 25: Flow pattern around the siphon and no flow separation in this area (100\% valve opening).

3.5.6. Investigation of Cavitation Phenomenon in Channel and Slot. Cavitation along the channel is usually checked based on a dimensionless number called the cavitation index $(\sigma)$.

The cavitation index is a function of local pressure and fluid velocity, and this index's critical value is $(0.2-0.25)$ along the channels and 0.2 inside the slots [38].

In the bottom outlet channels, when the gate opening is $100 \%$, the maximum velocity and, as a result, the maximum discharge capacity is created in the channel. Subsequently, the study and control of cavitation index in $100 \%$ opening is considered for this channel. Since the Sardab Dam will be built at an altitude of approximately 2500 meters above sea level and with an ambient temperature of approximately 20 degrees Celsius, to calculate the cavitation index, we will have 


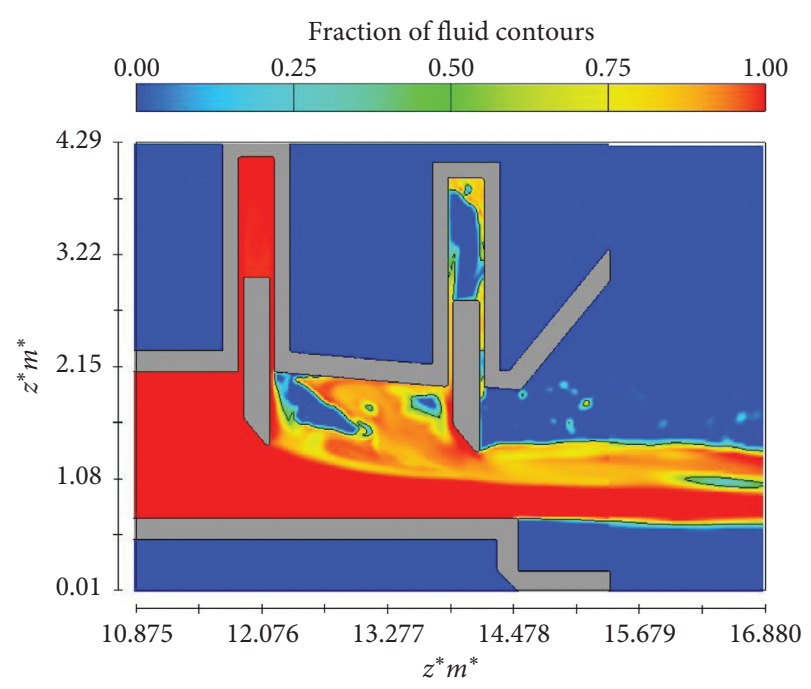

FIGURE 26: Fluid volume fraction contour between two gates in $50 \%$ opening state.

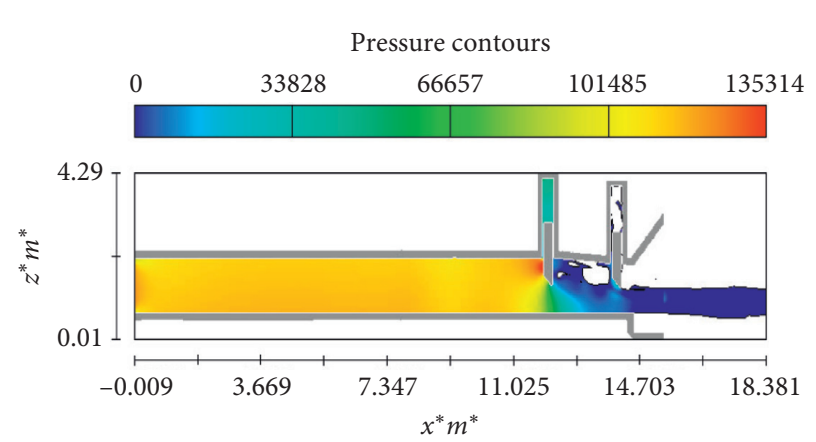

FIGURE 27: Pressure changes in the bottom outlet's tunnel of Sardab Dam at the time of $50 \%$ opening of service and emergency gates.

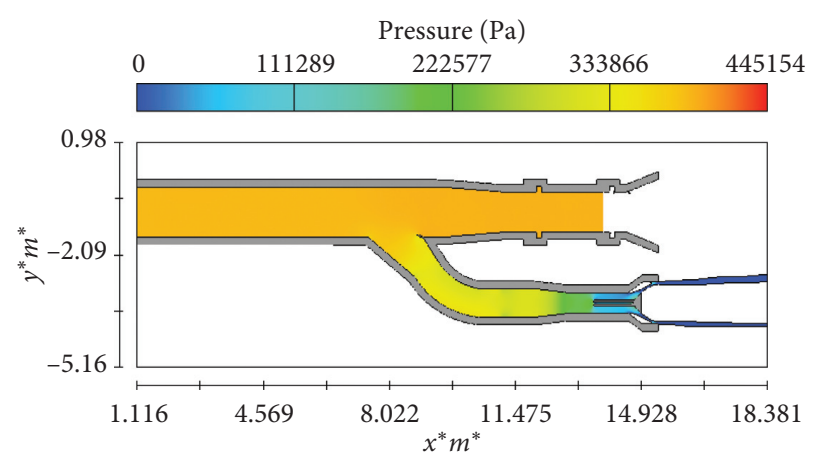

FIGURE 28: Pressure changes in the bottom outlet's tunnel of Sardab Dam for a fully closed gate and $100 \%$ open branch valve.

$$
\sigma=\frac{P_{\mathrm{abs}}-P_{v}}{(1 / 2) \rho \cdot V^{2}}
$$

where $\sigma$ is the cavitation index; $P_{\mathrm{abs}}=P_{i}+P_{\mathrm{bar}}$, in which $P_{\text {bar }}(\mathrm{Pa})$ is the atmosphere pressure; and $P_{i}(\mathrm{~Pa})$ is the relative pressure and $P_{v}$ is the vapor pressure of fluid.

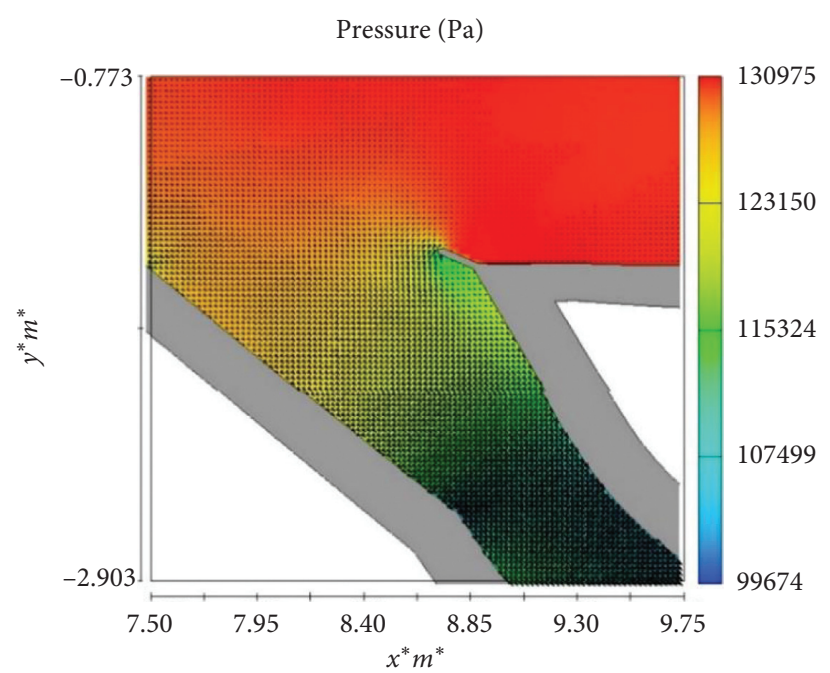

FIgURE 29: Pressure changes in the bottom outlet's branch area of the Sardab Dam for a fully closed gate and $100 \%$ open branch valve.

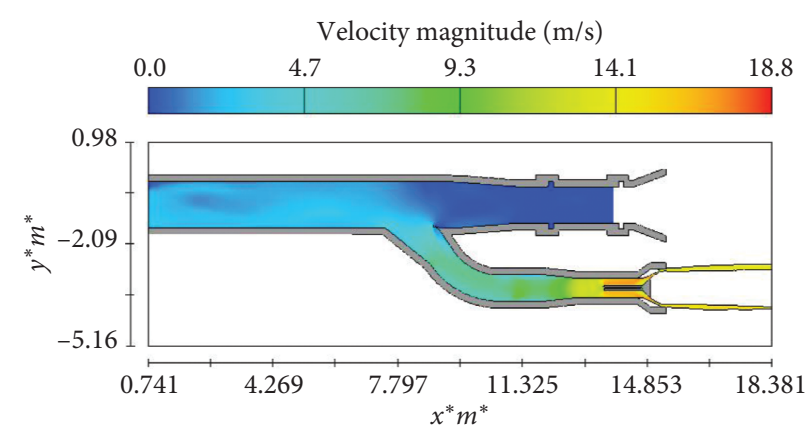

Figure 30: Velocity changes in the branch area for fully closed gate mode and $100 \%$ open branch valve.

Equation (9) is used to calculate atmospheric pressure:

$$
P_{\text {bar }}=P_{a}\left(1-\frac{B Z}{T_{0}}\right)^{g / R B} \text {. }
$$

The parameters' values of the above equation are defined as follows:

$$
\begin{aligned}
\frac{g}{R B} & =5.26, \\
T_{0} & =293.1 \mathrm{~K}, \\
B & =0.0065 \frac{\mathrm{K}}{\mathrm{m}}, \\
Z & =2500 \mathrm{~m}, \\
P_{a} & =\text { Sea level pressure. }
\end{aligned}
$$

For air-fluid, the value of $P_{\mathrm{bar}}=74 \mathrm{kPa}$ is considered using equation (9).

It should be noted that the fluid vapor pressure will be equal to $P_{v}=2.337 \mathrm{kPa}$ at this temperature. The cavitation index can be calculated with the help of pressure and velocity 
values in different conditions using the above parameters' values.

To calculate the relative pressure values of $P_{i}$, according to the specific values of the $51.35 \mathrm{~m}$ head, the velocity $V_{i}$ can be calculated with the help of the following equation. The loss values sum is based on the velocity values in the reference cross-section $V$, which has a cross-section equal to $A=1.25 \times 1.10=1.375 \mathrm{~m}^{2}$ :

$$
\begin{aligned}
P_{i} & =\rho g\left(H-\frac{V_{o}^{2}}{2 g}-\sum h_{i}\right), \\
\sum h_{o} & =\sum \xi \frac{V^{2}}{2 g} .
\end{aligned}
$$

Considering the flow head equal to $51.35 \mathrm{~m}$ for the two sections of the gate slot and the output section, there will be a flow (in the output section, the relative pressure is equal to zero, and the velocity is equal to $18.9 \mathrm{~m} / \mathrm{s}$ ).

At the output section,

$$
\sigma=\frac{P_{i}+P_{\mathrm{bar}}-P_{v}}{(1 / 2) \rho \cdot V^{2}} \approx 0.4 .
$$

Also, the cavitation values in the service gate slot, as one of the most critical points for cavitation occurrence, are calculated as follows:

$$
\begin{aligned}
P_{i} & =\rho g\left(H-\frac{V_{o}^{2}}{2 g}-\sum h_{i}\right) \approx 71 \mathrm{kPa}, \\
\sigma & =\frac{P_{i}+P_{\mathrm{bar}}-P_{v}}{(1 / 2) \rho \cdot V^{2}}=\approx 0.79 .
\end{aligned}
$$

The gate slot should be checked using the slot characteristics in order to examine the possibility of cavitation. Considering that the slot's retraction angle is $1: 12$ and $W / D=140 / 162=0.86$ and $\Delta / W=25 / 140=0.18$, the allowable index value is about 0.2 , and this index is about 0.79 in Sardab Dam's gate slot. Accordingly, cavitation will not happen in the slot [39-42].

Dam bottom outlets which contain valves and pumps play a vital role in dam operation and safety, as they allow controlling the water surface elevation below the spillway level. Probability of the formation of cavitation due to the concentrated vortices is too high. The vorticity distribution near the branch entrance exhibited high values due to the cylindrical shape of the bottom outlet which contributed to high amount of flow separation $[43,44]$. The transient flow features associated with a moving gate were successfully captured as well as the discharge characteristic for partial opening of the gate. For partial openings, water flows under the gate lip at high-velocity and drags the air downstream of the gate, which may cause damages due to cavitation and vibration. The results suggest that the Flow-3D can be useful for calculating the air demand in dam bottom outlets. In the case study presented, the appropriateness of the existing design was verified. For partial gate opening, the discharge varies with the square of gate opening, whereas for a fully opened gate, discharge varies with $H^{1 / 2}$. For new facilities, the possibilities of the Flow-3D for identifying the flow patterns and for computing the pressure and velocity fields should be helpful for designing the aeration system.

\section{Conclusion}

In the present study, Sardab Dam's bottom outlet and Howell Bunger valve's hydraulic performance in different opening conditions, including $20,40,60,80$, and $100 \%$, with different flow rates, was investigated. These examinations comprise the service gate's single operation, the service gate and the Howell Bunger valve's simultaneous operation, and the Howell Bunger valve's single operation. The results presented for different opening conditions for velocity values with $100 \%$ opening in the section below the gate is about $18 \mathrm{~m} / \mathrm{s}$, and the maximum velocity under the gate for $40 \%$ opening is equal to $23.1 \mathrm{~m} / \mathrm{s}$. The velocity values in the gate slot are about $2-3 \mathrm{~m} / \mathrm{s}$, in which case no flow separation and undesirable circular flow are observed in the slot. This condition is true for all gate openings. The velocity values at the branch entrance are variable $2-5 \mathrm{~m} / \mathrm{s}$, no flow separation and other adverse conditions occur in this area, and the velocity values increase after passing through the branch entrance. There is no undesirable change in the distribution of pressure along the tunnel and in the gate areas, and there is no drastic reduction of pressure in this area. It should be noted that there are no undesirable hydraulic phenomena in these sections, including flow separation and local vortices. For $50 \%$ opening of the gates in the gate's upper areas, the desired pressure values are reduced, and in the areas between the two gates, the pressure values are reduced. Moreover, with the installation of aerators, the possibility of cavitation in this area is reduced. For fully closed gate mode and $100 \%$ open branch valve, no circular flow and undesirable pressure changes are created in the tunnel. Also, the velocity behind the valves in the fully closed state is zero, and at the branch entrance point, it is $5-6 \mathrm{~m} / \mathrm{s}$. At the valve output, the velocity has increased by about $36 \%$ compared to when the gates are fully open. Based on these conditions, the branch valve's output flow rate is estimated to be about $5.3 \mathrm{~m} / \mathrm{s}$. The presented results show that due to the bottom outlet operation in the reservoir's maximum head condition, the probability of cavitation in the area between the two gates is very high. This analysis suggests that numerical modeling with the Flow-3D can be helpful for the design of this kind of hydraulic works.

\section{Data Availability}

All data used to support the findings of the study are included within the article.

\section{Disclosure}

This research received no specific grant from any funding agency in the public, commercial, or not-for-profit sectors.

\section{Conflicts of Interest}

The authors declare that there are no conflicts of interest regarding the publication of this paper. 


\section{References}

[1] F. Salazar, J. San-Mauro, M. Á. Celigueta, and E. Oñate, “Air demand estimation in bottom outlets with the particle finite element method," Computational Particle Mechanics, vol. 4, no. 3, pp. 345-356, 2016.

[2] M. Zounemat-Kermani and M. Scholz, "Computing air demand using the Takagi-Sugeno model for dam outlets," Water, vol. 5, no. 3, pp. 1441-1456, 2013.

[3] G. H. Chen, G. Y. Wang, C. L. Hu, B. Huang, and M. D. Zhang, "Observations and measurements on unsteady cavitating flows using a simultaneous sampling approach," Experiments in Fluids, vol. 56, no. 2, 2015.

[4] M. Karalar and M. Çavuşli, "Seismic effects of epicenter distance of earthquake on 3D damage performance of CG dam," Earthquakes and Structures, vol. 18, no. 2, pp. 201-213, 2020.

[5] M. Moradi, S. M. Aghajanzadeh, H. Mirzabozorg, and M. Alimohammadi, "Underwater explosion and its effects on nonlinear behavior of an arch dam," Coupled Systems Mechanics, vol. 7, no. 3, pp. 333-351, 2018.

[6] M. Karalar and M. Çavuşli, "Examination of 3D long-term viscoplastic behaviour of a CFR dam using special material models," Geomechanics and Engineering, vol. 17, no. 2, pp. 119-131, 2019.

[7] M. Karalar and M. Çavuşli, "Evaluation of 3D nonlinear earthquake behaviour of the Ilısu CFR dam under far-fault ground motions," Advances in Civil Engineering, vol. 2019, Article ID 7358710, 15 pages, 2019.

[8] O. A. Yamini, M. R. Kavianpour, and S. H. Mousavi, "Wave run-up and rundown on ACB Mats under granular and geotextile filters' condition," Marine Georesources \& Geotechnology, vol. 36, no. 8, pp. 895-906, 2017.

[9] J. Speerli and W. H. Hager, "Air-water flow in bottom outlets," Canadian Journal of Civil Engineering, vol. 27, no. 3, pp. 454-462, 2000.

[10] B. Fazelabdolabadi and M. H. Golestan, "Towards bayesian quantification of permeability in micro-scale porous structures-the database of micro networks," HighTech and Innovation Journal, vol. 1, no. 4, pp. 148-160, 2020.

[11] R. Touaibi, H. Koten, and O. Boydak, "Parametric study of an organic rankine cycle using different fluids," Emerging Science Journal, vol. 4, no. 2, pp. 122-128, 2020.

[12] G. Innella and P. A. Rodgers, "The benefits of a convergence between art and engineering," HighTech and Innovation Journal, vol. 2, no. 1, pp. 29-37, 2021.

[13] M. Sadat Helbar, A. Parvaresh Rizi, J. Farhoudi, and A. Mohammadi, "3D flow simulation to improve the design and operation of the dam bottom outlets," Arabian Journal of Geosciences, vol. 14, no. 2, 2021.

[14] B. K. Sreedhar, S. K. Albert, and A. B. Pandit, "Cavitation damage: theory and measurements-a review," Wear, vol. 372373, pp. 177-196, 2017.

[15] A. R. Sengupta, R. Gupta, and A. Biswas, "Computational fluid dynamics analysis of stove systems for cooking and drying of muga silk," Emerging Science Journal, vol. 3, no. 5, pp. 285-292, 2019.

[16] I. Ntintakis, G. E. Stavroulakis, and N. Plakia, "Topology optimization by the use of $3 \mathrm{D}$ printing technology in the product design process," HighTech and Innovation Journal, vol. 1, no. 4, pp. 161-171, 2020.

[17] J. Yang, P. Teng, Q. Xie, and S. Li, "Understanding water flows and air venting features of spillway-a case study," Water, vol. 12, no. 8, p. 2106, 2020.
[18] K. Kramer, W. H. Hager, and H.-E. Minor, "Development of air concentration on chute spillways," Journal of Hydraulic Engineering, vol. 132, no. 9, pp. 908-915, 2006.

[19] J. Lewin, Hydraulic Gates and Valves: In Free Surface Flow and Submerged Outlets, Thomas Telford, London, UK, 2001.

[20] R. Shilpakar, Z. Hua, B. Manandhar et al., "Numerical simulation on tunnel spillway of Jingping-I hydropower project with four aerators," IOP Conference Series: Earth and Environmental Science, vol. 82, Article ID 012013, 2017.

[21] F. Daneshmand, E. A. Yazdi, and Y. B. Lari, "Hydraulic model test of the bottom outlet of Sivand dam," in Proceedings of the 5th ISME/WSEAS International Conference on Fluid Mechanics and Aerodynamics, pp. 269-275, Athens, Greece, 2007.

[22] D. L. Vischer and W. H. Hagner, Dam Hydraulics, John Wiley \& Sons, London, UK, 1999.

[23] M. R. Kavianpour, The Reattaching Flow Downstream of Deflectors Including the Effect of Air Injection, Ph.D. dissertation, University of Manchester, Manchester, UK, 1997.

[24] S. Khazaei, R. Ellahi, E. Niknami, and K. Shahverdy, "Hydraulic analysis and cavitation cavitation phenomenon in physical and numerical models of the bottom outlet in Rudbar dam, Lorestan province, Iran," in Proceedings of the 36th IAHR World Congress, The Hague, the Netherlands, 2015.

[25] S.-P. Ruan, J.-H. Wu, W.-W. Wu, and R.-Z. Xi, "Hydraulic research of aerators on tunnel spillways," Journal of Hydrodynamics, vol. 19, no. 3, pp. 330-334, 2007.

[26] J.-H. Wu, S.-R. Feng, W.-W. Wu, and S.-P. Ruan, "Hydraulic characteristics of partial opening of the working gate for a discharge tunnel," Journal of Hydrodynamics, vol. 19, no. 4, pp. 488-493, 2007.

[27] J.-Y. Li, Z.-X. Gao, H. Wu, and Z.-J. Jin, "Numerical investigation of methodologies for cavitation suppression inside globe valves," Applied Sciences, vol. 10, no. 16, p. 5541, 2020.

[28] A. H. Nikseresht, N. Talebbeydokhti, and H. Khorshidi, "Three-dimensional numerical modeling of cavitation and aeration system in dam outlets," Journal of Fluids Engineering, vol. 134, no. 9, Article ID 091302, 2012.

[29] C. W. Hirt and B. D. Nichols, "Volume of fluid (VOF) method for the dynamics of free boundaries," Journal of Computational Physics, vol. 39, no. 1, pp. 201-225, 1981.

[30] J. H. Ferziger and M. Perić, "Computational methods for fluid dynamics," Computational Methods for Fluid Dynamics, Springer, Berlin, Germany, 2002.

[31] Flow Science, Inc., FLOW-3D User Manual Version 10.0.1.

[32] M. Nazari-Sharabian, A. Nazari-Sharabian, M. Karakouzian, and M. Karami, "Sacrificial piles as scour countermeasures in river bridges a numerical study using flow-3D," Civil Engineering Journal, vol. 6, no. 6, pp. 1091-1103, 2020.

[33] N. J. H. Al-Mansori and L. S. A. Al-Zubaidi, "One-dimensional hydrodynamic modeling of the euphrates river and prediction of hydraulic parameters," Civil Engineering Journal, vol. 6, no. 6, pp. 1074-1090, 2020.

[34] T. M. Taher and A. O. Anwar, "Effects of gate lip orientation on bottom pressure coefficient of dam tunnel gate," Arabian Journal for Science and Engineering, vol. 41, no. 12, pp. 4927-4936, 2016.

[35] B. Dargahi, "Flow characteristics of bottom outlets with moving gates," Journal of Hydraulic Research, vol. 48, no. 4, pp. 476-482, 2010.

[36] H. Wang, "Turbulence and air entrainment in hydraulic jumps," Ph.D. dissertation, The University of Queensland, Brisbane, Australia, 2014.

[37] R. Narayanan, "The role of pressure fluctuations in hydraulic modelling," in Proceedings of the Symposium on Scale Effects in 
Modelling Hydraulic Structures, Congress IAHR, Essilngenam Neckar, Germany, September 1984.

[38] H. T. Falvey, Cavitation in Chutes and Spillways, Engineering Monograph 42, Water Resources Technical Publication, US Printing Office, Bureau of Reclamation, Washington, DC, USA, 1990.

[39] M. Ghaderi, "Study of rehabilitation plan of bottom outlet service and emergency gates of Karun 1 dam," Dams and Reservoirs, vol. 30, no. 3, pp. 91-96, 2020.

[40] C. Liu, Q. Yan, and H. G. Wood, "Numerical investigation of passive cavitation control using a slot on a three-dimensional hydrofoil," International Journal of Numerical Methods for Heat \& Fluid Flow, vol. 30, no. 7, pp. 3585-3605, 2019.

[41] T. Smajdorová and D. Noskievičová, "Methodology for the application of nonparametric control charts into practice," Emerging Science Journal, vol. 4, no. 4, pp. 272-282, 2020.

[42] C. V. Davis and K. E. Sorensen, Handbook of Applied Hydraulics, vol. 22, pp. 22-66, McGraw-Hill Book Company, New York, NY, USA, 1969.

[43] X. Song and C. Liu, "Experimental investigation of floorattached vortex effects on the pressure pulsation at the bottom of the axial flow pump sump," Renewable Energy, vol. 145, pp. 2327-2336, 2020.

[44] T. A. Norizan, E. Reda, and Z. Harun, "Enhancement of vorticity reduction by floor splitter in pump sump to improve pump efficiency," Sustainable Energy Technologies and Assessments, vol. 26, pp. 28-36, 2018. 